\title{
An Experts' Perspective on Enterprise Architecture Goals, Framework Adoption and Benefit Assessment
}

\author{
Matthias Lange and Jan Mendling \\ Humboldt-University Berlin \\ Institute of Information Systems \\ Berlin, Germany \\ matthias.lange@wiwi.hu-berlin.de and jan.mendling@wiwi.hu-berlin.de
}

\begin{abstract}
In recent years, enterprise architecture (EA) management has become an intensively discussed approach in both industry and academia for managing the complexity of an enterprise from a holistic perspective. While there is a strong academic and practical interest in EA frameworks and EA modeling, there is a notable insecurity about the cost benefit ratio of EA. In this paper, we address this research problem with a qualitative research design. We conduct a series of semistructured interviews with industry experts on enterprise architecture in order to identify classes of EA goals, corresponding EA frameworks adoption to achieve these goals and employed EA benefit assessment approaches. The findings point to, among others, a fairly stable set of EA goals that shift over time and EA frameworks that lack modularity and adjustment capabilities to easily customize towards these goals. This paper is part of an ongoing exploratory research that aims at researching which benefits emanate from EA.
\end{abstract}

Keywords - Enterprise Architecture, EA Goals, EA frameworks, EA benefit assessment, Expert Interviews

\section{INTRODUCTION}

Understanding, engineering, and managing the complexity is crucial to achieve and sustain success of an enterprise [1]. In recent years, enterprise architecture (EA) management has become an intensively discussed approach in both industry and academia for managing complexity of an enterprise from a holistic perspective. Enterprise architecture initiatives typically cover different perspectives in order to provide a well-defined alignment between business processes and IT [2, 3].

While there is a strong academic and practical interest in EA frameworks [e.g. 4, 5] and EA modeling [e.g. 6], there is a notable insecurity about the cost benefit ratio of EA [7]. Presumably, this observation relates to the fact that there is currently no commonly-agreed upon role of EA in an enterprise setting [8] and no common understanding of the goals being addressed with EA altogether [9]. Consequently, it is crucial to develop research insight into EA initiatives and their contribution to EA goals in order to leverage the benefits and proliferation of EA in practice [7].

In this paper, we address this problem with a qualitative research design. We conduct a series of semi-structured interviews with industry experts on enterprise architecture in order to identify classes of EA goals, corresponding EA frameworks adoption to achieve these goals, and employed EA benefit assessment approaches. More specifically, the contribution of this paper is to answer three research questions a) which goals do companies aim to achieve over time when they set up and maintain EA initiatives, b) in which way do companies adopt available EA frameworks and modeling methods for achieving particular sets of goals, and c) how do companies measure the achievement of the set goals? Our results suggest that EA goals are shifting with increasing maturity of EA initiatives.

The remainder of the paper is structured accordingly. In Section 2, we provide an overview of EA goals from the perspective of related research along with a discussion of EA frameworks and their analysis capabilities. Section 3 describes our research method. We provide demographics of those experts who participated in the interviews and discuss our qualitative data analysis. Section 4 presents the findings, first regarding the types of EA goals and then their relation to EA adoption and EA benefit assessment. Section 5 concludes the paper with a discussion of implications for research and practice.

\section{BACKGROUND}

In the following section, we present our literature review related to our research. First, Section II.A covers EA goals and Section II.B outlines the results on EA frameworks. Finally, Section II.C outlines literature about EA goals.

\section{A. Enterprise Architecture goals}

Various researchers notice that EA is a term broadly defined and used by both scholarly authors [e.g. 8, 10] as well as practitioners [11]: From a more CIO-oriented perspective such as in [7] over [12] seeing EA clearly as a business issue concerned with 'the high-level logic for business processes and IT capabilities' to defining EA as a common business- and IT-related 'strategic approach which takes a systems perspective, viewing the entire enterprise as a holistic system encompassing multiple views such as organization view, process view, knowledge view, and enabling information technology view in an integrated framework' [1].

Similarly broad are goals associated with EA. In his recent publication, Schönherr [8] identifies different EA goals covering literature until early 2008. Kappelman et al. [9], Lankhorst [13], Op't Land [14], Ross et al. [12] and 
Salmans and Kappelman [15] also list various EA goals in more recent publications. Based on these publications, we have compiled the following list of published EA goals. Compared to the original list proposed by Schönherr [8], we added to this list the EA goal agility that was named in various publications and we consolidated all goals based on regulatory requirements in one category as they have the same underlying goal. The resulting list is shown in Table I.

TABLE I. EA GOALS AS IDENTIFIED IN LITERATURE BASED ON [8]

\begin{tabular}{|c|c|c|c|}
\hline EA goal & & $\begin{array}{c}\text { Additional literature } \\
\text { identified } \\
\text { compared to }[8]\end{array}$ & $\begin{array}{l}\text { Total iden- } \\
\text { tified litera- } \\
\text { ture (count) }\end{array}$ \\
\hline \multirow{6}{*}{ Internal } & $\begin{array}{l}\text { Business-IT } \\
\text { alignment }\end{array}$ & {$[10,13-15]$} & 14 \\
\hline & Cost reduction & {$[10,12-15]$} & 8 \\
\hline & $\begin{array}{l}\text { Standardization/ } \\
\text { consolidation }\end{array}$ & {$[12,13,15]$} & 5 \\
\hline & $\begin{array}{l}\text { Management/ } \\
\text { governance }\end{array}$ & {$[10,12]$} & 4 \\
\hline & Agility & {$[10,13-15]$} & 4 \\
\hline & $\begin{array}{l}\text { Miscellaneous } \\
\text { (e.g. risk) }\end{array}$ & [10] & 7 \\
\hline External & $\begin{array}{l}\text { Regulatory } \\
\text { compliance }\end{array}$ & {$[13]$} & 13 \\
\hline
\end{tabular}

Schönherr [8] divides the EA goals into two categories: external, regulatory-driven EA goals that aim at fulfilling various regulatory requirements (such as SoX or Basel II compliance) and internal EA goals that are manifold: Business-IT alignment aims at bringing business requirements in line with IT implementation, cost reduction aims at mainly reducing IT-related but also business process related costs, standardization/consolidation shall remove complexity from the architecture to improve cost and project delivery such as time-to-market, management/governance shall improve the decision making as well as processes along business and IT decision makers, agility aims at improving both process as well as IT flexibility to adjust easily to new market situations, and finally miscellaneous goals are mainly supporting other business functions such as risk management and business continuity management. Noticeably, the here identified EA goals are mainly IT goals that support in fact enterprise goals. This is an indicator of how EA is positioned today, namely in the IT departments of an organization. Additionally, in most EA publications, only a single, specific EA goal is discussed in one paper - if mentioned at all [e.g.16].

As goals and their priority can change over time, maturity models try to explain and predict the change of goals along with other changing parameters [17]. In the field of EA there are only very few maturity models to date [18]: Ross [19] proposes a maturity model that is currently the most cited and applied model [20]. It is comprised of four stages: First the business silo stage is shaped by individual and mostly not integrated application development and operation. Then the standardized technology stage aims at standardizing and consolidating the IT landscape to realize cost effectiveness and operational efficiency. Third the optimized core stage aims at further increasing cost effectiveness and operational efficiency by standardizing processes and data. And finally the business modularity stage aims at improving flexibility of adjustments to new requirements by establishing a "plug-and-play" capability of changing business processes and the underlying IT.

\section{B. EA frameworks}

The implementation and conduct of various EA components contributes towards achieving the discussed EA goals. Both academics as well as practitioners propose and discuss various EA frameworks. These EA frameworks provide guidance on how to conduct and structure an EA. The four most cited and best known frameworks are the Zachman framework [21], the TOGAF framework [22], the DoDAF framework [23] and the ARIS framework [24, 25]. Although all these frameworks are called EA frameworks they vary significantly and the term is used very ambiguously. For example, the four here named EA frameworks are mostly combinations of enterprise ontologies and EA process methodologies that also specify various tools, models, and artifacts. Hereby, Zachman's is only an enterprise ontology with no process or tooling implications. Additionally, the scope of these EA frameworks is about designing and building enterprise-wide information systems rather than managing and optimizing enterprises as a whole. Therefore, these frameworks are often combined or adjusted to specific needs in practice [26].

Nevertheless, there are some elements all these frameworks have in common. Most EA frameworks provide architecture description techniques and the associated modeling techniques, but do not specify a specific modeling language [13]. All four are model-based approaches. Hereby, complexity-reducing models are used as a mean for documentation of existing as-is structures, as a blueprint for to-be structures, as a language to communicate changes or gain alignment, or as a basis for decision making structuring available information and comparing competing scenarios [27]. These models are comprised of various entities (e.g. applications, software components, process capabilities, data objects, etc.) that represent real-world objects of the enterprise at hand. To manage this huge amount of entities, EA frameworks use architecture layers and architecture views to further reduce the complexity of entities involved in EA models [5].

The definition of the EA layers varies depending on the employed EA framework. According to Winter and Fischer [28] most frameworks differentiate the following five layers: The business architecture comprises the fundamental principles of an organization describing among others the strategy, organizational goals, value networks, or offered services/products. The process architecture focuses on the business functions and their orchestration to develop, create, and deliver services/products describing for example required business processes, related organizational structures, responsibilities and performance indicators. The integration architecture models the interaction and interconnection of information system components describing e.g. application classes, integration systems, and data flows. The software architecture comprises software artifacts describing e.g. services and data structures. The 
infrastructure architecture focuses on technological aspects of computing and communication describing for example infrastructure services and infrastructure organization.

In addition to architectural layers, architectural views adjust EA models to the particular needs of a stakeholder. Therefore, architectural views leave out unnecessary information and filter the EA model only for stakeholders' concerns at hand. The parts of an EA model visible to a specific stakeholder are therefore completely dependent on the stakeholder [13 pp. 57-58].

Once available, the models can be used to analyze and optimize the EA. Bucher et al. [29] report on eight different analysis approaches used to gain deeper insights:

- Coverage analysis identifies redundancies and gaps by matching two or more layers.

- Dependency analysis investigates the relations between different EA entities, both on one layer and between layers.

- Heterogeneity analysis identifies similar entities implemented in variants or on different platforms that should be reconsidered for standardization.

- Interface analysis typically focuses on the evaluation of the relationship and interfaces within one class of entities (e.g. technical interfaces between software applications).

- Complexity analysis relates strongly to dependency, heterogeneity, and interface analysis and considers in addition aspects such as modularity.

- Compliance analysis leverage the transparency created with EA to identify gaps to certain policies and regulatory law (e.g. Solvency II or Basel II).

- Cost analysis assigns cost to certain EA entities and allows the calculation of the financial impact of changing the architecture.

- Benefit analysis is the complementary analysis to cost analysis, identifying how certain EA entities contribute to organizational goals and create benefits for the organization.

\section{EA benefit assessment}

EA benefit assessment approaches help to understand to what degree the EA goals of an organization are achieved. The scope for EA benefit assessment varies depending on the decision context and requirements of an EA function: It ranges from evaluating the overall benefits of an EA function over assessing EA models to assessing future states of architecture elements. Literature discusses three different areas of EA benefit assessment:

Firstly, 'EA scenario assessment' approaches are concerned with assessing enterprise architectures for their fit with organizational goals and their requirements. To evaluate the enterprise architectures, these approaches either analyze EA models or gathered information about the EA in a structured way [30]. Existing research in this area focuses on the integration of quantitative information in existing modeling approaches as well as the research of decision making procedures and approaches to support rational decision making. Also different decision making contexts, e.g. system availability and system performance analysis, have been researched in detail [e.g. 2, 31].

Secondly, 'EA process assessment' approaches are concerned with evaluating the conduct of EA processes within an EA function. The processes should be evaluated whether they are complete, efficient and purposeful in terms of the organization's goals [e.g. 32, 33]. However, the research in this area is just starting and, to the best of the authors' knowledge, approaches to evaluate the overall EA process landscape are not available yet. Being especially discussed by some practitioners and consultancies, literature from the area of EA maturity and non-scientific publications $[34,35]$ might include such EA process evaluation aspects, but these do not provide such an evaluation approach either.

Thirdly, 'Overall EA benefit assessment' approaches are concerned with an holistic assessment of EA benefits. The research in the area evolves around three areas: The research of EA value drivers [e.g. 36, 37], IS success models in the context of EA [38, 39], and a concept for the overall assessment of an EA function against an EA reference model [e.g. 40-43].

\section{RESEARCH OBJECTIVES AND METHOD}

In this section, we outline our research objectives and method used in this research. Section III.A presents the underlying research objectives in light of the literature review. Section III.B discusses the details of the semistructured expert interviews and in Section III.C our qualitative data analysis approach is outlined.

\section{A. Research objectives}

As our literature review reveals and also supported by Salmans and Kappelman [15], EA and especially EA goals is a field of research with a gap of empirical studies, in which theoretical foundations are hardly established. Therefore, a qualitative research design using semi-structured interviews is a promising starting point to build theory [44, 45].

In this research, we use semi-structured interviews with industry experts to compare the findings about EA goals and EA frameworks from our literature review with current state of practice and to generate theories from it [46]. More specifically, we identify classes of EA goals and corresponding EA frameworks adoption to achieve these goals by investigating the three research questions a) which goals do companies aim to achieve over time in practice when they set up and maintain EA initiatives, b) in which way do companies adopt available EA frameworks and modeling methods for achieving particular sets of goals, and c) how do companies measure the achievement of the set goals?

\section{B. Expert interview conduct}

Being the most common source to gather information in qualitative IS research, we conducted semi-structured interviews with 16 industry experts to gain insights in what EA goals and EA frameworks are used in practice today [45]. Using semi-structured interviews allows interviewees 
TABLE II. SUMMARY OF EXPERTS INTERVIEWED

\begin{tabular}{llll}
\hline Expert ID & \multicolumn{1}{c}{$\begin{array}{c}\text { Interview } \\
\text { Mode }\end{array}$} & \multicolumn{1}{c}{ Industry } & \multicolumn{1}{c}{ Employees } \\
\hline Exp. 1 & Face-to-face & Retail & $10,001-50,000$ \\
Exp. 2 & Telephone & Consulting & N/A \\
Exp. 3 & Telephone & Banking & $10,001-50,000$ \\
Exp. 4 & Face-to-face & Telecom & $>50,000$ \\
Exp. 5 & Face-to-face & Retail & $10,001-50,000$ \\
Exp. 6 & Face-to-face & Retail & $>50,000$ \\
Exp. 7 & Telephone & Consulting & N/A \\
Exp. 8 & Face-to-face & Healthcare & $5,000-10,000$ \\
Exp. 9 & Face-to-face & Telecom & $5,000-10,000$ \\
Exp. 10 & Face-to-face & Consulting & N/A \\
Exp. 11 & Face-to-face & Healthcare & $>50,000$ \\
Exp. 12 & Telephone & Insurance & $>50,000$ \\
Exp. 13 & Telephone & Banking & $<5,000$ \\
Exp. 14 & Telephone & Consulting & N/A \\
Exp. 15 & Telephone & Telecom & $>50,000$ \\
Exp. 16 & Telephone & Banking & $>50,000$ \\
\hline
\end{tabular}

to think and reflect about topics, themes and developments in a new way by linking their experiences and perceptions [47].

In this research, the 16 interviewed EA experts covered both EA experts from enterprises on a senior manager level (mostly "Head of Enterprise Architecture" or equivalent) as well as experienced consultants to complement the experiences from the enterprises. These interviewees were identified through a judgmental procedure using factors such as years of experience in EA, reputation in the community and position in the organization. We compiled a list of experts based on these factors by searching the internet platform XING and personal contacts. Thereby, the experienced EA consultants were identified based on their experience and reputation mainly in the German EA community. Based on these criteria, we developed a list of 54 EA experts and contacted the experts individually. A face-to-face or telephone interview was then set up with 16 of these experts who were willing to participate. A summary of these 16 contacted experts is shown in Table II.

The interviews took place throughout a period of four months (between August and November 2010). Each interview took approx. 60 to 90 minutes. As 8 of the 16 experts were located to far away, we conducted these interviews by telephone. However, long-term studies show that telephone interviews are as effective as face-to-face interviews [48]. The sample is well distributed among different industries and enterprise size. Covering retail, banking, healthcare, telecom and insurance, the average is 2.4 experts per industry. As $50 \%$ of the involved enterprises employ more than 50,000 employees, the interviews covered mainly large enterprises. Four experienced EA consultants having worked in various industries complement the experts involved from industry. Among these participating experts, we have not seen any systematic omissions or a bias in the responses.
TABLE III. GUIDING QUESTIONS PER INTERVIEW SECTION

$\begin{array}{ll}\text { Section 1. } & \begin{array}{l}\text { Demographics } \\ \text { What are your enterprise's demographics? What is your } \\ \text { personal experience with EA? }\end{array} \\ \text { Section 2. } & \text { EA goals } \\ \text { Wection } 3 . & \text { EA frameworks } \\ & \text { What corresponding EA frameworks are employed to } \\ \text { achieve these goals? } & \\ \text { Section 4. } & \text { EA quality } \\ & \text { How does this EA analysis approach support you to reach } \\ \text { your (EA) goals? } & \\ \text { What are employed measures of quality? }\end{array}$

The interview guide for the semi-structured interviews covered four sections as shown in Table III. After designing the interview guide, we pilot tested it with the first two experts resulting in minor changes that we incorporated. ${ }^{1}$

\section{Data analysis}

To analyze the data gathered in the interviews, we used an approach using the qualitative data analysis tool NVivo 9 as suggested by Bandara et al. [49]. For the coding in this tool, we used a bottom-up approach where all inferences were derived purely from the data, not considering a priori notions or constructs in the coding process. Coding the gathered data this way, we assigned tags or labels, in NVivo terms 'notes', as units of meaning to the descriptive or inferential information of the interviews [47]. To do so, we modeled our interview guide in NVivo 9 by creating a folder for each interview question first. Then, we analyzed the transcribed interviews by coding them as followed:

- When a new answer to a question emerged, a new node was created and assigned to the question

- Statements generally supporting a certain thought were assigned to these nodes

Two researchers coded the interviews subsequently. The first researcher coded the interviews including the initial node structure. Then, the other researcher re-coded the interviews against the created structure. With this approach, we could identify only few discrepancies. To resolve these discrepancies, we discussed and recoded the nodes according to a common consensus. Subsequently, the NVivo tool allowed us to run basic statistical analysis on the clustered data.

\section{RESEARCH FINDINGS}

In the following section, we present our findings from our expert interviews. Section IV.A covers the results on EA goals, followed by section IV.B which discusses the findings on EA frameworks. Finally section IV.C presents our findings about EA benefit assessment. Whenever applicable in the following section, direct quotes from the experts are depicted as 'quote'. Minor editions are made to these quotes if required. These quotes are shown as $<$ edition $>$.

\footnotetext{
${ }^{1}$ The complete survey is omitted in this paper due to space reasons but is available upon request.
} 
TABLE IV. Statistics of EA GOAls

\begin{tabular}{lllll}
\hline \multicolumn{1}{c}{ EA goal } & $\begin{array}{c}\text { Total } \\
\text { Count (\%) }\end{array}$ & $\begin{array}{c}\text { Enterprise } \\
\text { Count (\%) }\end{array}$ & $\begin{array}{c}\text { Consultant } \\
\text { Count (\%) }\end{array}$ \\
\hline \multirow{6}{*}{ Internal } & Transparency & $15(93.8 \%)$ & $11(91.7 \%)$ & $4(100.0 \%)$ \\
& Complexity management & $14(87.5 \%)$ & $11(91.7 \%)$ & $3(75.0 \%)$ \\
& Governance or transformation/ & $14(87.5 \%)$ & $11(91.7 \%)$ & $3(75.0 \%)$ \\
& IT management & $13(81.3 \%)$ & $10(83.3 \%)$ & $3(75.0 \%)$ \\
& Business/IT Alignment & $4(25.0 \%)$ & $3(25.0 \%)$ & $1(25.0 \%)$ \\
& Agility & $4(25.0 \%)$ & $3(25.0 \%)$ & $1(25.0 \%)$ \\
& Innovation & $1(6.3 \%)$ & $0(0 \%)$ & $1(25.0 \%)$ \\
\hline External & Other business support & & & $1(25.0 \%)$ \\
\hline
\end{tabular}

\section{A. EA goals}

The interviewed experts, both experts from enterprises as well as consultants, reported on a fairly stable set of EA goals as can be seen in Table IV.

Experts reported that they employ EA in most settings to get a holistic view on the IT landscape as well as supported business processes by creating transparency. Then, they use this holistic view to manage complexity, i.e. consolidate IT applications or standardize processes. Third-frequently, EA is used to manage both the IT landscape as well as transformation projects. Business/IT alignment plays an important role in most settings and is reported as a goal concurrent and inherent to the other 3 most frequently named goals. In contrast to these goals, the remaining goals are significantly less frequently named. Agility is named only by 3 EA experts from industry and by 1 EA consultant. Expert 2 might give a reason for this as he states that architecture should be inherently lasting and stable so that it enables the applications to be agile'. This indicates that agility could be more a topic of individual software applications rather than of the EA that needs to provide a stable vision of a target architecture. Similarly, experts hardly name compliance to regulatory requirements as well as the support of other business functions such as risk management. Most industry experts report of a separate department or a business function that has historically grown and primarily responsible for this area. Consequently, EA has no or only a very minor role. Only Expert 1 reports to have a compliance manager in his EA management function.

Comparing this list of EA goals derived from the expert interviews with the list derived from literature shows that on the one hand 'cost reduction' is not listed as a separate EA goal and on the other hand the new EA goal 'innovation' emerges. Although cost reduction is an EA goal that experts mentioned, it is eminent to all other EA goals and hence inherently included in all these 8 goals. The EA goal 'innovation' seems not covered to the best of the authors' knowledge by current literature.

Notably, most of the identified goals are similar to the identified goals in literature IT goals that support enterprise goals where EA is the employed tool to achieve the underlying enterprise goals. This fact that most of the goals reported by the experts are IT goals is an indication about the immature state of the discipline as also reported by Salmans and Kappelman [15].
Having identified this fairly stable set of EA goals, we analyzed how EA goals and the associated priorities changed over time and how they are expected by the experts to change in the future. For this analysis, we analyzed past, current, and future goals of the interviewed organizations as shown in Table VI and clustered the different goals with an agglomerative hierarchical clustering approach. As a result we identified 4 goal classes that can be differentiated:

- Goal class 1 "Create baseline": The first class of goals focuses on understanding the organization's landscapes and their interrelations in order to improve cost efficiency. Most organizations report that the need to gain transparency on their legacy structures triggered their EA activities. With this transparency they aim to reduce costs by decommissioning not-required or redundant assets (e.g. applications or infrastructure components). Additionally, the gained transparency allows aligning business and IT especially in the context of ongoing projects.

- Goal class 2 "Manage complexity": The second class of goals aims primarily at managing complexity. By engineering a target EA and defining EA principles, complexity shall be removed from the as-is architecture step-by-step and also be avoided in the future by considering prospective requirements. Hereby, a target EA is developed based on the transparency of the legacy described in goal class 1 . In this class, business/IT alignment also plays an important role to define a target architecture that adapts both business and IT requirements.

- Goal class 3 "Drive transformation": The third class of EA goals is to improve and actively manage the delivery of the target EA from a holistic perspective in terms of effectiveness and efficiency. EA experts state that they see the EA functions increasingly involved in transformation projects implementing the target EA by either supporting or consulting the transformation or program management to achieve architectural goals as well as improving the efficiency of the projects overall. Expert 3 states that 'EA should move towards a quality management function for transformations similar to lean or six sigma that is used in operative areas of enterprises for quality management'. 
- Goal class 4 "Support innovation": The primary goal of this fourth goal class is to support innovation from an EA perspective. Hereby, the EA needs to provide, on the one hand, a stable set of capabilities that allows to operate and to implement the EA in an efficient way; but on the other hand, needs to highlight and support situations where architectural changes can improve and innovate the business. Being an important part of the innovation process, the tight alignment between business and IT as well as improving and managing the transformation or program management plays an additional role in this class.

Further analyzing the change over time in these goal classes, we found that organizations seem to develop along our identified goal classes starting with class 1, evolving over 2 and 3 to goal class 4. Table VI shows the key statistics for this: While $50 \%$ of the organizations are in goal class 2 "Manage complexity" today, according to experts' projections, $41.7 \%$ have the aspiration to move to class 3 "Drive transformation". Experts report on a similar movement in the past: $83.4 \%$ of the enterprises have started in goal class 1 "Create baseline" and evolved from there to goal class 2 "Managing complexity" or further. The average age of the EA function supports this development over time: From goal class 1 to 4 the average age of the EA functions is increasing. Only goal class 3 seems to be an outlier with a higher average than goal class 4 though.

Comparing these findings with the maturity model suggested by Ross [34], these findings can be seen as complementary to the suggested maturity model. While Ross [34] has the overall management of IT (and in later maturity stages of IT-related business processes as well) in focus, we discussed EA goals as the goals of an EA function. Consequently, we interviewed the heads of such functions only. These well-established EA functions are in Ross's maturity model a key characteristic of stage 4, the last stage of the model. Therefore, our findings complement this last stage and detail how an EA function in this stage develops their goals over time.

\section{B. EA frameworks}

Discussing EA frameworks with the interviewed experts showed that there are less common elements when it comes to this topic. All experts reported that they are using an individual customized approach as an EA framework. To build these individual EA frameworks, they leveraged certain elements of the available general ones such as TOGAF, ARIS or Zachman. Interestingly, our findings show that the most referenced EA framework is TOGAF followed by ARIS, while Zachman and the DoD framework were subordinated. Even 3 enterprises report to have their complete individual approach:
TABLE V. REFERENCE FOR OWN CUSTOMIZED EA FRAMEWORK

\begin{tabular}{ll}
\hline \multicolumn{1}{c}{ EA framework } & \multicolumn{1}{c}{$\begin{array}{c}\text { Share of organizations using EA } \\
\text { framework as a reference }\end{array}$} \\
\hline TOGAF & $8(66.7 \%)$ \\
ARIS & $3(25 \%)$ \\
Zachman & $1(8.3 \%)$ \\
DoD & $0(0 \%)$ \\
Other & $0(0 \%)$ \\
None & $3(25 \%)$ \\
\hline
\end{tabular}

Although organizations leverage existing EA frameworks to create their individual approach, $75.0 \%$ of the experts state that they see a lack of customizable elements in the frameworks and also a lack of advice how to tailor the EA frameworks to their organizational needs.

Similarly heterogeneous are the findings about the layers employed within the organizations. While Winter and Fischer [28] distinguished between 5 different layers, the experts in our interviews differentiated between business, application and infrastructure layer in practice only. Some $(25 \%)$ report on having a data layer as well. Consequently, the interviewed experts combine business architecture and process architecture in one layer as well as software architecture and integration architecture. Discussing these 3 layers with the experts, we identified 4 different occurrences:

- Business \& IT modeling in depth: On all 3 layers, business, application and infrastructure is modeled in a fairly deep level. A focus is set on the application layer though. Artifacts on the business layer are modeled rather high-level and are not persistently linked to the other layers.

- Business \& IT modeling in high-level: Modeling from an EA point of view is done mainly on the business and application layer not going in depth. The focus is on considering all relevant assets and their interrelations rather than describing all assets in depth. The infrastructure layer is hardly or only on a infrastructure type level rather than infrastructure instance level modeled.

- Divided Business \& IT in depth: Modeling is done on the business and IT layer, both in depth, similar to the first occurrence. However, there is hardly a link between both layers (e.g. because of different modeling divisions or different used tools).

- Divided Business \& IT in high-level: Similarly to the business \& IT modeling in high-level, the focus in this occurrence is on the business and application layer with a similar modeling depth. However, the link between both layers is not persistently linked and may be rather high-level.

Discussing these different layers, $81.3 \%$ of the experts' belief that the infrastructure layer becomes less important as infrastructure is more and more a commodity that can be highly standardized. $25.0 \%$ of the experts belief that infrastructure should only be modeled for EA purposes at a maximum as infrastructure types and not as infrastructure instances $56.3 \%$ belief that it plays almost no role in the future. 
TABLE VI. KEY STATISTICS OF GOAL CLASSES

\begin{tabular}{ccccc}
\hline & $\begin{array}{c}\text { Total organizations } \\
\text { currently or in the } \\
\text { past in class } \\
\text { (in \%) }\end{array}$ & $\begin{array}{c}\text { Share of } \\
\text { organizations } \\
\text { currently in class } \\
\text { (in \%) }\end{array}$ & $\begin{array}{c}\text { Share of experts' } \\
\text { aspiration to be in } \\
\text { class in the future } \\
\text { (in \%) }\end{array}$ & $\begin{array}{c}\text { Today's average } \\
\text { age of EA function } \\
\text { (in years) }\end{array}$ \\
\hline Goal class 1: Create Baseline & 83.4 & 25.0 & 16.7 & 3.7 \\
Goal class 2: Manage complexity & 50.0 & 50.0 & 16.7 & 4.8 \\
Goal class 3: Drive transformation & 16.7 & 16.7 & 41.7 & 6.5 \\
Goal class 4 Support innovation & 8.3 & 8.3 & 25.0 & 7.0 \\
\hline
\end{tabular}

Discussing the depth of the modeling, experts agreed that the level of detail for modeled entities can remain for EA on a rather high level and should only go into detail when demand rises from projects. These findings are in line with Aier [50]: EA should be responsible for modeling a holistic picture and should focus on the interactions and interrelationships of an enterprise's entities on a broader rather than deeper level. The modeling depth is then created in concrete implementation or transformation projects along with the requirements engineering.

As disclosed by the different occurrences of architectural layers, the link between business and application layer seems to be the most challenging: $88.3 \%$ report to have both not yet sufficiently linked. This concerns, on the one hand, the link between business processes and the underlying applications, but also on the business layer link between goals and business processes that then in turn can be linked to applications. Expert 9 reports here on a recent project to introduce an additional layer, the alignment layer, that links the business and IT layer explicitly. He states that "this new layer allows <us> to make a link between business and IT while we can still accommodate that business and IT will always have different terminologies and wordings." Nevertheless, the priority to get this interface right is not only supported by the omnipresent EA goal of business/IT alignment that is present in all above discussed goal classes but also supported by the modeling focus on the business and application layer as well as the interface between.

Having identified the above described 4 different modeling occurrences, we compared them with the EA goal classes the organizations are in at the moment. Thereby, we identified the following modeling patterns dependent from the current goal focus:

- $67 \%$ of the experts in the goal class 1 "Understanding" typically report to model on all (business, application and infrastructure) layers. Here, the focus is mostly on IT which might be due to the fact that transparency needs to be created first to gain a basic understanding.

- In the goal class 2 "Engineering", the focus shifts to the business and application layer as typically reported by $87 \%$ of the experts.

- Then, in goal class 3 "Managing" the modeling approach is reported to be typically on a higher level of the business and application layer compared to goal class 2 as reported by $83 \%$ of the experts. Only project-specific deep dives are done as needed by transformation projects.
- And finally in the goal class 4 "Innovating" the modeling on a high level business and application layer remains as described for goal class 3 but additionally a stronger focus is set on data. Expert 10 argues that this is "due to the business enabling and innovating effect of centralized easy to access data that can be used in all business processes".

While all enterprises had specified EA layers and related modeling approaches that can be associated with the EA goal classes, standardized analysis approaches are only reported by Expert 11: "We first specify well in advance what analyses or end products we need and base our work, especially the modeling of EA artifacts, on this demand." The other experts report that they use EA as well to conduct certain analysis. However, they are not standardized, rather ad-hoc and focus only on visualizing information rather than gaining new insights. The experts see a demand for these standardized analyses but link this to the need to mature in other areas of EA first. "Standardized and well-defined analyses would allow me to focus my activities on EA aspects that are relevant in certain situations" remarks Expert 8. However, Expert 13 sees the need to "first $<\ldots>$ mature in terms of our EA processes to be able to routinely conduct such analyses".

Summarizing our findings related to EA frameworks, experts belief that the layering of EA is well applied, but other than this the elements of EA frameworks such as modeling specification and analysis approaches lack in practice a modular, customizable approach.

\section{Current practice of EA benefit assessment}

All interviewed experts, both experts from enterprises as well as consultants, reported that they neither measure objectively the benefits derived from EA nor do they use any structured approach to assess or track such. However, they see the need and demand for such measures and approaches as shown in the Table VII.

TABLE VII. STATISTICS OF ANSWER TO QUESTION "HOW IMPORTANT IS MEASURING THE QUALITY OF YOUR EA FOR YOUR ORGANIZATION/YOUR CLIENTS?"

\begin{tabular}{ll}
\hline \multicolumn{1}{c}{ Answer } & \multicolumn{1}{c}{ Count (\%) } \\
\hline 1 - not important at all & $0(0 \%)$ \\
- rarely important & $1(6.3 \%)$ \\
3 - somewhat important & $1(6.3 \%)$ \\
4 - important & $11(68.8 \%)$ \\
5 - very important & $3(18.8 \%)$ \\
\hline
\end{tabular}

$87.6 \%$ of the experts state that measuring the quality of EA is important to their organization/their clients. Expert 13 even 
emphasizes this situation: 'Unfortunately the only measure we have is the sensed amount of disasters'. And Expert 2 adds 'I mean unless we do a big mistake with the thing we call architecture $\langle\ldots>$ and given the fact that organizations need to change continuously nowadays, having a well functioning transformation process including your architecture process is becoming almost as important as having a good and well running primary process. So where we use lean six sigma to optimize the operational process, we also need to use similar measures to optimize and mature the transformation process. ' Our experts explain the reasons for this gap between perceived importance and current as detailed in Table VIII.

TABLE VIII. REASONS GIVEN IN INTERVIEW FOR CURRENT PRACTICE OF EA BENEFIT ASSESSMENT

\begin{tabular}{ll}
\hline \multicolumn{1}{c}{ Answer } & \multicolumn{1}{c}{ Count (\%) } \\
\hline Current maturity stage & $12(75.0 \%)$ \\
Missing metrics & $11(68.8 \%)$ \\
Missing approach & $11(68.8 \%)$ \\
No data at hand & $5(37.5 \%)$ \\
Too complex and unique decision making situations & $5(37.5 \%)$ \\
Too long-term consequences & $3(18.8 \%)$ \\
Too academic & $2(12.5 \%)$ \\
\hline
\end{tabular}

Most experts report that they currently do not assess EA benefits due to their current maturity stage of their EA function. Expert 1 states this as follows 'We simply have due to our maturity, as we are a relatively young function, other priorities at the moment. And we are not in the need to do so at the moment.' The second most named reasons are that the experts are neither aware of metrics to assess the benefits of EA nor of approaches or frameworks to do so. Expert 14 emphasizes this and also refers to the next reason, missing data at hand ' $\langle W e\rangle$ are struggling quite a lot to define measurements for enterprise architecture and the next step to gather the data I have not seen any implementation on this.' Expert 4 illustrates the next reason 'There is rarely one situation like the other. We have very complex situations where we can't compare two similar companies having chosen different options'. Further named reasons are that the assessment of EA benefits can be seen after years and is influenced by many other decisions. Additionally, some experts fear that such an assessment would be seen by the organization as too academic as it is very cumbersome.

Having identified these reasons for the gap between perceived importance and current practice, we analyzed what experts would like to be able to measure in the future to close this gap. Here, we identified three different areas of EA assessment that are of concern to the experts:

- EA processes: The first named area is an assessment of the processes within the EA function. Experts want to assess whether they are doing the right things and missing no major aspects of EA as well as evaluating the effectiveness and efficiency of these processes. This comprises more an assessment of the input (done EA activities) rather than the outcome.

- EA scenarios: The second named area is approaches to assess different scenarios or options for enterprise architectures when they have to make an architectural decision. Experts report that they are defining EA principles or guidelines as a basis for these decisions as well as calculating business cases but '...decisions are mostly based on experience and gut feeling rather than objective criteria...' as Expert 8 states. And 'whether a decision was right or not can only be seen years later' as Expert 9 adds. This area tries to estimated both the required inputs as well as the derived outcomes by the overall or parts of the aimed target architecture for an organization. It represents an assessment of future states and is hence more a forecast.

- EA success: Finally, the third area named by the experts is the overall assessment of benefits for the organization gained by EA. Experts referring to this area aim at justifying the EA function by showing what value has emanated ultimately to the organization from the EA function. In contrast to the previous two areas, this assessment shall provide the overall picture of used inputs and the resulting achieved outcomes. It is hence an assessment of the results of the EA function.

With these three EA assessment areas in mind, we analyzed how these relate to the four goal classes introduced in Section IV.A and the related perceived importance of EA benefit assessment.

TABLE IX. DESIRED EA BENEFIT ASSESSMENT DEPENDING ON CURRENT GOAL CLASS

\begin{tabular}{|c|c|c|c|}
\hline \multirow[b]{2}{*}{ Goal class (GC) } & \multicolumn{3}{|c|}{ EA benefit assessment of } \\
\hline & $\begin{array}{c}E A \\
\text { processes } \\
\text { in count } \\
\text { (\%) }\end{array}$ & $\begin{array}{c}E A \\
\text { scenarios } \\
\text { in count }(\%)\end{array}$ & $\begin{array}{c}\text { EA success } \\
\text { in count } \\
(\%)\end{array}$ \\
\hline GC 1: Create Baseline & $2(66.7 \%)$ & $1(33.3 \%)$ & $0(0.0 \%)$ \\
\hline GC 2: Manage complexity & $2(33.3 \%)$ & $3(50.0 \%)$ & $1(16.7 \%)$ \\
\hline GC 3: Drive transformation & $0(0.0 \%)$ & $2(100 \%)$ & $0(0.0 \%)$ \\
\hline GC 4: Support innovation & $0(0.0 \%)$ & $0(0.0 \%)$ & $1(100.0 \%)$ \\
\hline
\end{tabular}

In this analysis, a tendency can be seen that with increasing maturity the desired EA benefit assessment area shifts from an EA process evaluation over the assessment of EA scenarios to the overall EA success assessment - or in other words from input based to an outcome based measurement. Furthermore, the evaluation of EA scenarios is especially in those scenarios relevant, where the transformation plays a focal role.

\section{IMPLICATIONS, LIMITATIONS AND FUTURE RESEARCH}

This paper presented an experts' perspective on EA goals and corresponding EA framework adoption to achieve these goals as well as employed EA benefit assessment approaches. We found that a stable set of EA goals can be identified among the interviewed experts. Based on this set of EA goals, four different EA goal classes can be distinguished and to each of these corresponds one of four identified modeling focuses. Although in practice currently EA benefit assessment is hardly conducted, the need and requirements for such seem to shift with the goal classes as well. In this following last section, we discuss the 
implications (Section V.A), limitations (Section V.B), and future research (Section V.C).

\section{A. Implications for research and practice}

The findings from this research have three immediate implications for research: First, we observe a difference of emphasis between goals mentioned in related research and according to experts' opinion. While in scientific publications, regulatory compliance occurs as a goal almost as often as any other topic, experts mentioned this topic only twice. A potential explanation suggested in the interviews is that the compliance function is typically not integrated in the EA function. If this would be the case on a larger scale, it does not seem to be appropriate to emphasize synergies between EA and compliance management in research, as this synergy would usually not materialize. Second, the interface between the business and the IT layer seems to require a more detailed understanding on how to drive the alignment and effectively integrate both. Experts stress a lack of methods and approaches to tackle alignment, and they formulate a need to measure the results of the alignment activities. Concerning this point, it would be worthwhile to adapt existing approaches from software quality and business process management where extensive sets of quality metrics have been proposed. Transferring Luftman and Brier's research on business alignment to the domain of EA might be another starting point for further research [51]. And third, the three main reasons why EA benefit assessment is currently hardly employed in practice - current maturity stage, missing metrics, missing approaches - indicate areas of research that seem to be valuable extensions of existing research. As current research does not accommodate the different requirements of EA maturity stages, an extension of existing approaches by such capabilities might lead to a better acceptance and usage of such adjustable approaches in practice.

Considering the implications of this research for practice, EA goal classes can be utilized by practitioners as a reference frame to a) analyze their current status of EA activities and b) determine what their target EA goal class is. Based on this, one can derive a roadmap on how to move from their current position towards the target class. Based on the EA framework-related findings, practitioners can further analyze their current modeling approach and adjust it accordingly. Here, an end product-driven, customized approach, as outlined above, can help to focus the activities.

\section{B. Limitations}

The insights presented in this paper are based on interviews with a limited number of 16 experts. To validate the findings on a larger scale, the sample needs to be further increased and broadened. Among others, we need to expand the geographical coverage of experts, which are currently recruited mainly from Germany. Furthermore, we currently rely on the internet platform XING and personal contacts to find interviewees, which calls for additional channels of contact. Finally, we consider an extension of the study towards experts from other industries. The presented research is focused on EA goals and modeling aspects only.
In order to elaborate on the goal classes and their characteristics, further factors such as EA governance, the EA processes, and EA products need to be considered.

\section{Future research}

In our future research, we aim to develop the identified EA goal classes towards a complementary maturity model to the model proposed by Ross [34]. On the one hand, this requires a detailed specification of this model and a thorough validation. This validation needs to be based on detailed case studies to investigate the findings from our interviews in more detail. On the other hand, our insights might also spark further research on the set of the following research questions. In terms of managing complexity, how can the benefits emanating from EA be measured and communicated? Regarding transformation management, how can EA management improve transformations and their delivery? Towards support of innovations, how can EA be used to support innovation? And how can EA be linked to business functions related to the area of innovation, both in business as well as in IT?

Considering our findings related to the EA frameworks, we see the need to further research the idea of customizable and modularized EA frameworks that can be adopted easily to enterprises' situations and their set EA goals respectively. Such an 'EA toolbox' could help enterprises to identify and customize their individual EA approach easily. Buckl et al. propose a pattern catalogue that picks up this idea [52]. Here, we need to understand further how enterprises can effectively chose from a set of EA modules, and which standardized analyses should complement these EA modules.

\section{REFERENCES}

[1] D. J. Nightingale and D. H. Rhodes, Enterprise Systems Architecting: Emerging Art and Science within Engineering Systems.2004.

[2] P. Johnson, R. Lagerström, P. Narman, and M. Simonsson, "Extended Influence Diagrams for Enterprise Architecture Analysis," Proceedings of the 10th IEEE International Enterprise Distributed Object Computing Conference, pp. 3-12, 2006.

[3] P. Närman, P. Johnson, M. Ekstedt, M. Chenine, and J. Konig, "Enterprise Architecture Analysis for Data Accuracy Assessments," Proceedings of the 13th IEEE International Enterprise Distributed Object Computing Conference, pp. 24-33, 2009.

[4] N. Lim, T.-G. Lee, and S.-G. Park, "A Comparative Analysis of Enterprise Architecture Frameworks Based on EA Quality Attributes," Proceedings of the 10th ACIS International Conference on Software Engineering, Artificial Intelligences, Networking and Parallel/Distributed Computing, pp. 283-288, 2009.

[5] J. Schekkerman, How to survive in the jungle of enterprise architecture frameworks: Creating or choosing an enterprise architecture framework. Victoria, B.C: Trafford, 2006.

[6] F. Arbab, F. S. de Boer, M. M. Bonsangue, M. M. Lankhorst, E. Proper, and L. van der Torre, "Integrating Architectural Models: Symbolic, Semantic and Subjective Models in Enterprise Architecture," Enterprise Modelling and IS Architecture, vol. 2, no. 1, pp. 40-56, 2007.

[7] P. Johnson, M. Ekstedt, E. Silva, and L. Plazaola, "Using Enterprise Architecture for CIO Decision-Making," Proceedings of the 2nd Annual Conference on Systems Engineering Research, 2004.

[8] M. Schönherr, "Towards a Common Terminology in the Discipline of Enterprise Architecture," Lecture Notes in Computer Science, vol. 5472, pp. 400-413, 2009.

[9] L. A. Kappelman, T. McGinnis, A. Pettite, and A. Sidorova, "Enterprise Architecture: Charting the Territory for Academic Research," 
Proceedings of the 14th Americas Conference on Information Systems, 2008.

[10] L. A. Kappelman, T. McGinnis, A. Pettite, B. Salmans, and A. Sidorova, "Enterprise Architecture: Charting the Territory for Academic Research," in The SIM guide to enterprise architecture, L. A. Kappelman, Ed, Boca Raton. Fla: CRC Press, 2010, pp. 96-110.

[11] A. Drobik, "Enterprise Architecture: The Business Issues and Drivers," Gartner August, 2002.

[12] J. W. Ross, P. Weill, and D. C. Robertson, Enterprise architecture as strategy: Creating a foundation for business execution. Boston, Mass: Harvard Business School Press, 2009.

[13] M. M. Lankhorst, J. Dietz, E. Proper, J. Tribolet, T. Halpin, J. Hoogervorst, M. Op 't Land, R. G. Ross, and R. Winter, Enterprise Architecture at Work: Modelling, Communication and Analysis. Berlin, Heidelberg: Springer Verlag, 2009.

[14] M. Op 't Land, E. Proper, M. Waage, J. Cloo, and C. Steghuis, Enterprise Architecture: Creating Value by Informed Governance. Berlin, Heidelberg: Springer Verlag, 2009.

[15]B. Salmans and L. A. Kappelman, "The State of EA: Progress, Not Perfection," in The SIM guide to enterprise architecture, L. A. Kappelman, Ed, Boca Raton. Fla: CRC Press, 2010, pp. 165-187.

[16] W. Boh, I. Fonga, and D. Yellin, "Using Enterprise Architecture Standards in Managing Information Technology," Journal of Management Information Systems, vol. 23, no. 3, pp. 163-207, 2007.

[17] M. Rosemann and T. de Bruin, "Towards a business process management maturity model," Proceedings of the 13th European Conference on Information Systems (ECIS 2005), pp. 25-35, 2005.

[18] B. Salmans, "EA Maturity Models," in The SIM guide to enterprise architecture, L. A. Kappelman, Ed, Boca Raton. Fla: CRC Press, 2010, pp. $89-95$.

[19] J. W. Ross, "Enterprise Architecture: Driving Business Benefits from IT," 2006.

[20] V. Venkatesh, H. Bala, and S. Venkatraman, "Enterprise Architecture Maturity: The story of the veterans health administration," MIS Quarterly Executive, vol. 6, no. 2, pp. 79-90, 2007.

[21] J. A. Zachman, "A Framework for Information Systems Architecture," IBM Systems Journal, vol. 26, no. 3, pp. 454-470, 1987.

[22] The Open Group, The Open Group Architecture Framework, Version 8 Enterprise Edition. Reading, U.K, 2005.

[23] D. O. D. A. F. Group, DoD Architecture Framework Version 1.0, 2004.

[24] A.-W. Scheer, ARIS - Business Process Frameworks. Berlin et al: Springer Verlag, 1999.

[25] IDS Scheer, Enterprise Architectures and ARIS Process Platform. Saarbrücken, 2005.

[26]R. Sessions, "A Comparison of the Top Four Enterprise-Architecture Methodologies," 2007.

[27] K. Smolander, M. Rossi, and S. Purao, "Software architectures: Blueprint, Literature, Language or Decision?," European Journal of Information Systems, vol. 17, no. 6, pp. 575-588, 2008.

[28] R. Winter and R. Fischer, "Essential Layers, Artifacts, and Dependencies of Enterprise Architecture," Journal of Enterprise Architecture, vol. 2007, no. May, pp. 1-12, 2007.

[29] T. Bucher, R. Fischer, S. Kurpjuweit, and R. Winter, "Analysis and Application Scenarios of Enterprise Architecture: An Exploratory Study," Enterprise Distributed Object Computing Conference Workshops, 2006. EDOCW'06. 10th IEEE International.

[30] M. R. Davoudi, F. Shams Aliee, and K. Badie, "An AHP-based approach toward enterprise architecture analysis based on enterprise architecture quality attributes," Knowledge and InfSys, 2010.

[31]R. Lagerström, P. Johnson, and P. Närman, "Extended Influence Diagram Generation for Interoperability Analysis," Enterprise Interoperability II, no. 5, pp. 599-602, 2007.

[32] A. Hirvonen, T. Oyj, and M. Pulkkinen, "Evaluation of Enterprise IT Architecture Solutions-How can an ICT consultant tell what is best for you?," Proceedings of the 10th European Conference on Information Technology Evaluation, 2003.

[33] T. Ylimäki, E. Niemi, and N. Hämäläinen, "Enterprise Architecture Compliance: The Viewpoint of Evaluation," Proceedings of the European Conference on Information Management and Evaluation, 2007.
[34] J. W. Ross, "Maturity Matters: How Firms Generate Value From Enterprise Architecture," Information Systems, vol IV, 2006.

[35] United States General Accounting Office, A Framework for Assessing and Improving Enterprise Architecture Management (Version 1.1) Executive Guide, 2003, pp. 233-241.

[36] V. Boucharas, M. van Steenbergen, S. Jansen, and S. Brinkkemper, "The Contribution of Enterprise Architecture to the Achievement of Organizational Goals: A Review of the Evidence," Proceedings of the 5th Trends in Enterprise Architecture Research Conference, 2010.

[37] M. van Steenbergen et al, "Modeling the Contribution of Enterprise Architecture Practice to the Achievement of Business Goals," Information Systems Development, 2010.

[38] W. H. DeLone and E. R. McLean, "The DeLone and McLean Model of Information Systems Success: A Ten-Year Update," Journal of Management Information Systems, vol. 19, no. 4, pp. 9-30, 2003.

[39] C. Kluge, A. Dietzsch, and M. Rosemann, "How to realise corporate value from Enterprise Architecture," Proceedings of the 14th European Conference on Information Systems, 2006.

[40] B. van der Raadt, R. Slot, and H. van Vliet, "Experience Report: Assessing a Global Financial Services Company on its Enterprise Architecture Effectiveness Using NAOMI," Proceedings of the 40th Annual Hawaii International Conference on System Sciences (HICSS'07), pp. 218-228, 2007.

[41]B. van der Raadt, H. van Vliet, E. Proper, F. Harmsen, and J. L. G. Dietz, "Assessing the Efficiency of the Enterprise Architecture Function," Advances in Enterprise Engineering II: First NAF Academy Working Conference on Practice-Driven Research on Enterprise Transformation, PRET 2009, Held at CAiSE 2009, 2009.

[42] B. van der Raadt, J. F. Hoorn, and H. van Vliet, "Alignment and maturity are silibings in architecture assessment," Proceedings of the 17th International Conference on Advanced Information Systems Engineering, pp. 357-371, 2005.

[43]B. van der Raadt, M. Bonnet, S. Schouten, and H. van Vliet, "The relation between EA effectiveness and stakeholder satisfaction," Journal of Systems and Software, vol. 83, pp. 1954-1969, 2010.

[44]P. R. Newsted, S. Huff, M. Munro, and A. Schwarz, "Introduction to Survey Instruments," MISQ Discovery, 1998.

[45] A. Pinsonneault and K. L. Kraemer, "Survey research methodology in management information systems: an assessment," Journal of Management Information Systems, vol. 10, no. 2, pp. 75-105, 1993.

[46] M. K. Kramp, "Exploring life and experience through narrative inquiry," in Foundations for research: Methods in education and the social science, K. de Marrais and S. D. Lapan, Eds, Mahwah, NJ: Erlbaum, 2004, pp. 103-121.

[47] M. B. Miles and A. M. Huberman, Qualitative data analysis: A source book of new methods: Sage Publications, 1984.

[48]F. T. Rogers, "Interviews by Telephone and in Person: Quality of Response and Field performance," The Public Opinion Quaterly, vol. 40, no. 1, pp. 51-65, 1976.

[49] W. Bandara, M. Indulska, S. Chong, and S. Sadiq, "Major Issues in Business Process Management: An Expert Perspective," Proceedings of the 15th European Conference on Information Systems, vol. 2007, pp. $1240-1251,2007$.

[50] S. Aier, S. Kurpjuweit, J. Saat, and R. Winter, "Enterprise Architecture Design as an Engineering Discipline," AIS Transactions on Enterprise Systems, vol. 1, no. 1, pp. 36-43, 2009.

[51] J. Luftman and T. Brier, "Achieving and Sustaining Business-IT Alignment," California Management Review, vol. 42, no. I, 1999.

[52] Buckl et al, "Enterprise Architecture Management Patterns -Exemplifying the Approach," Proceedings of the 12th International IEEE Enterprise Distributed Object Computing Conference, 2008.

\section{ACKNOWLEDGMENT}

The authors would like to thank the all involved EA experts for their time and support for this study. 